\title{
Recurrent, Large, Extraskeletal Osteosarcoma at the Back
}

\author{
Muhammad Danish Muneeb1 and Mirza Agha Naushad Baig² \\ IDepartment of General Surgery, Baqai Medical University, Karachi, Pakistan \\ 2Department of General Surgery, Zubaida Medical Centre, Karachi, Pakistan
}

\begin{abstract}
Extraskeletal osteosarcoma is a rarely identified variety of sarcomas throughout the world, which is still a dilemma for the surgeons' community with respect to its diagnosis and treatment. It is slow-growing in nature, and attains a huge size usually at presentation, which puts the clinician in jeopardy with regard to its management. Our case is the first of its variety documented in Pakistan. A 70-year male patient presented with a $19 \mathrm{~cm}$ mass at the back, as a recurrent tumor. We did the excisional biopsy of the mass, followed by complete removal with intact margins. Histopathology revealed extraskeletal osteosarcoma as the final diagnosis. We suggest that this tumor should be included in the differential diagnosis of all large, recurrent soft tissue masses in the body.
\end{abstract}

Key Words: Extraskeletal, Osteosarcoma, Recurrent.

How to cite this article: Muneeb MD, Baig MAN. Recurrent, large, extraskeletal osteosarcoma at the back. J Coll Physicians Surg Pak 2019; 29(Supplement 2):S138-S140.

\section{INTRODUCTION}

The extraskeletal osteosarcoma has been known among surgeons' community since 1941, when Wilson first specified this disease. ${ }^{1}$ Extraskeletal osteosarcoma is a rare tumor, which defines itself in $1 \%$ of all soft tissue sarcomas and $4 \%$ of all osteogenic sarcomas. The etiology of trauma in the development of extraskeletal osteosarcoma is not clear; however, patients sometimes relate the swelling to the trauma. The presentation can be either painful or painless enlarging mass. Extraskeletal osteosarcomas are usually found at around 40 years of age and above ${ }^{2}$, mostly predominating in male population. The most commonly occurring site of extraskeletal osteosarcoma is thigh in $48 \%$ of cases, followed by upper limb region, $23 \%$; retroperitoneum, $17 \%$; and trunk, $11 \% .3$ It is called as a soft-tissue sarcoma as it is completely separated from the bone and periosteum, which is amalgamated in malignant osteoid. 4 The prognosis for extraskeletal osteosarcoma is usually poor and adequate surgery with wide surgical excision has a statistically positive impact on prognosis. ${ }^{5}$

\section{CASE REPORT}

A 70-year healthy male, with no known comorbids, presented in outpatient clinic, at a private hospital in

Correspondence to: Dr. Muhammad Danish Muneeb,

Department of General Surgery, Baqai Medical University,

Karachi, Pakistan

E-mail: danishmuneeb@yahoo.com

Received: April 11, 2019; Revised: July 16, 2019;

Accepted: July 27, 2019
November 2018. Presentation was as painless, slowly enlarging mass at the right side of upper back, which attained the size of rugby ball, hindering his sleep and lying supine (Figure 1). According to the patient, he was operated one year back at the same region. Around six months later, the enlarging mass produced uncomfortable feeling and difficulty in daily works. During physical examination, the movements of right and left shoulder girdles were normal. The pain sensations were intact and there was no vascular compromise. The swelling had a size starting from the level of C-7 vertebra above and reaching the level of $10^{\text {th }}$ rib below. It was on the right side of upper back and overriding the midline. It was $19 \times 14.5 \times 10 \mathrm{~cm}$ in dimensions. The swelling was firm, unattached to the overlying skin, and not freely mobile over the underlying structures. The scar mark of the previous surgery was visible on preoperative examination.

The patient was prepared for surgery and medical and anesthetic fitness were sought. Informed verbal and written consent was taken both for the surgery and for the pictures and details of the case to be included. One pint of whole blood was arranged. After general anesthesia, the patient was prepared on the table in prone position. Incision was given vertically, cranial to caudal direction, lengthwise. The mass was encroaching the right scapula and abutting back muscles in that region. Complete removal of the tumor was possible by sharp dissections throughout, with the help of scissors and diathermy (Figure 2). Hemostasis was secured during and after the procedure. The cavity was washed with pyodine and normal saline. Two redivac drains were 


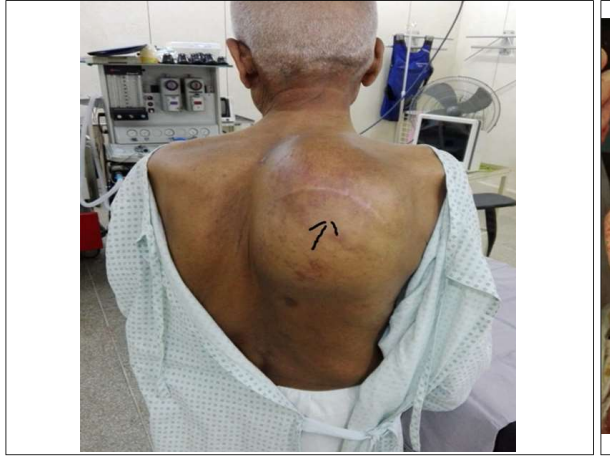

Figure 1: Posterior view, mass at upper right back, crossing the midline to left. Arrow points to the previous surgery scar.

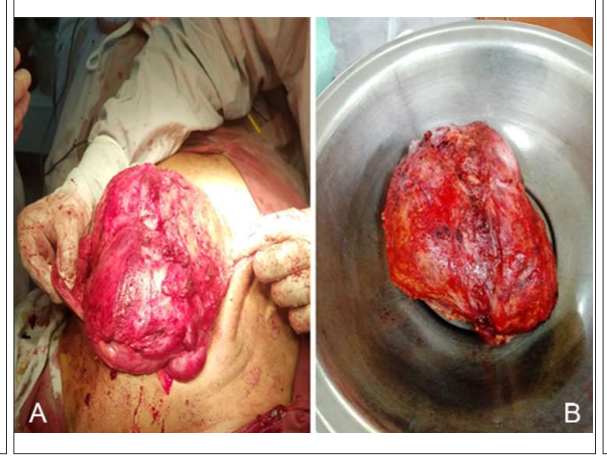

Figure 2: (A) Patient in prone position on the operating table, showing the mass, with skin flaps raised. (B) Completely removed mass in large dish.

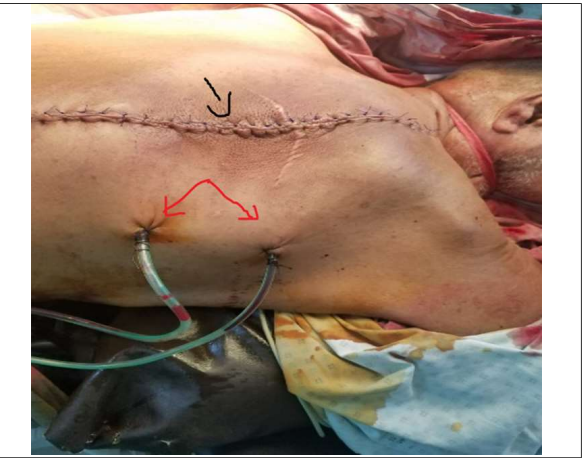

Figure 3: Peroperative picture, with stitched upper vertical line (black arrow), with 2 redivac drains (red arrow), placed in the cavity. placed in the cavity (Figure 3 ). The wound was closed with relaxed flaps, and skin was closed and dressed. The histopathology of the mass showed extraskeletal osteosarcoma, similar to the previous one. The margins were free of tumor. The postoperative follow-up visit was satisfactory. The condition of the patient till date is stable with no systemic signs of any illness. There are no signs of local recurrence at the operated side on physical examination. The patient was advised for follow-up after every 3 months with an ultrasound doppler of the operated region. Computerised tomography (CT) scan was also advised at 6 months to 1 year follow-up visit.

\section{DISCUSSION}

Extraskeletal osteosarcoma is a malignant tumor with anaplastic spindle cells; however, some low-grade extraskeletal osteosarcomas are also defined in literature. Since 1953, around 6 cases of low-grade extraskeletal osteosarcoma have been reported in studies.

Describing it further, it has been presumed that extraskeletal osteosarcoma develops from the myositis ossificans circumscripta (MOC), ${ }^{6}$ which also comes in the differential diagnosis. In MOC, a specific architecture is seen, having spindle cells along with chondroid component, and bone cells, which either are mature or immature. A "zonal phenomenon" is called when there is clearly benign reactive rim of mature bone at the periphery, and a central area of immature bone interlaced with chondroid and osteoid matrix.

In literature search, around 53 patients of extraskeletal osteosarcoma were identified during 30 years. ${ }^{7}$ Within these 53 patients, 41 involved extremeties, 51 were high-grade tumors, and 40 were more than $5 \mathrm{~cm}$ in dimensions. Wide surgical resection had been shown to be the essence of treatment in all cases; however, 19 patients pertained only to surgery in a literature search. Radio and chemotherapy did not show any enhanced survival in these cases. For patients presenting with localised extraskeletal osteosarcoma, 3-year event-free survival was found but was higher for patients with superficial tumors and negative margins at resection.
Tumour-free margins and superficially localised extraskeletal osteosarcomas are good prognostic signs with even a higher than 3-year event-free survival rates. ${ }^{8}$

Tumor size was once thought to be the predictor of survival; however, some recent groups define wide tumor resection, a tool for achieving $66-77 \%$ survival rate, which reaches in its prognosis to its bony counter-part, skeletal osteosarcoma. ${ }^{9}$

The tumor usually begins its life with a slow evolution, and the diagnosis, therefore, might be delayed for up to 10 years and the presentation is sometimes of a giantsized tumor, which might reach $30 \mathrm{~cm}$. Those patients who had tumors of volume $>500 \mathrm{cc}$, showed a survival of 18.7 months compared to 13.7 months with lower volume masses, which was not statistically significant. 10 This tumor also has the capacity to recur, which was observed in $45-50 \%$ patients in a study. These are the important aspects which are hurdles in the early diagnosis of this very rare tumor, which seems to hibernate and disguise itself as a benign lesion, just like myositis ossificans. That is why misdiagnosis is a killer, and surgery is the only curative resort for these tumors, at the right time and with heroic decision.

Seven cases of low grade extraskeletal osteosarcoma have been reported, in which all except three were in the limb region. ${ }^{11}$ Our case is one of its variety, being recurrent and low grade, and largest in its position and dimension in the region of girdle and just above right scapula. A definitive surgery for this large tumor is an 'art and craft' for the surgeon and its cure lies in en-masse removal.

\section{PATIENT'S CONSENT:}

The informed and written consent was taken for preoperative detailed counselling and for the follow-up visits as well.

\section{CONFLICT OF INTEREST:}

Authors declared no conflict of interest.

\section{AUTHORS' CONTRIBUTION:}

MDM: Patient selection, surgery, paper writing, editing. MANB: Patient selection, surgery. 


\section{REFERENCES}

1. Wilson H. Extraskeletal ossifying tumors. Ann Surg 1941; 113: 95-112.

2. Lee JS, Fetsch JF, Wasdhal DA, Lee BP, Pritchard DJ, Nascimento AG. A review of 40 patients with extraskeletal osteosarcoma. Cancer 1995; 76:2253-9.

3. Ahmad SA, Patel SR, Ballo MT, Baker TP, Yasko AW, Wang X, et al. Extraosseous osteosarcoma: Response to treatment and longterm outcome. J Clin Oncol 2002; 20:521-7.

4. Hoch M, Ali S, Agrawal S, Wang C, Khurana JS. Extraskeletal osteosarcoma: A case report and review of the literature. J Radiol Case Rep 2013; 7:15-23.

5. Berner K, Bjerkehagen B, Bruland OS, Berner A. Extraskeletal osteosarcoma in Norway, between 1975 and 2009, and a brief review of the literature. Anticancer Res 2015; 35:2129-40.

6. Luczyyska E, Kasperkiewicz H, Domalik A, Cwierz A, BobekBillewicz $B$. Myositis ossificans mimicking sarcoma, the importance of diagnostic imaging - case report. Pol J Radiol 2014; 79:228-32.
7. Choi LE, Healey JH, Kuk D, Brennan MF. Analysis of outcomes in extraskeletal osteosarcoma: A review of fifty-three cases. J Bone Joint Surg Am 2014; 96:e2.

8. Tamura T, Suzuki K, Yasuda T, Nogami S, Watanabe K, Kanamori $\mathrm{M}$, et al. Extraskeletal osteosarcoma arising in the subcutaneous tissue of the lower leg: A case report and literature review. Mol Clin Oncol 2018; 9:287-92.

9. Torigoe T, Yazawa Y, Takagi T, Terakado A, Kurosawa H. Extraskeletal osteosarcoma in Japan: Multiinstitutional study of 20 patients from the Japanese Musculoskeletal Oncology Group. J Orthop Sci 2007; 12:424-9.

10. Nystrom LM, Reimer NB, Reith JD, Scarborough MT, Gibbs Jr CP. The treatment and outcomes of extraskeletal osteosarcoma: Institutional experience and review of the literature. Iowa Orthop J 2016; 36:98-103.

11. Sabatier R, Bouvier C, de Pinieux G, Sarran A, Brenot-Rossi I, Pedeutour $\mathrm{F}$, et al. Low-grade extraskeletal osteosarcoma of the chest wall: Case report and review of literature. BMC Cancer 2010; 10:645. 